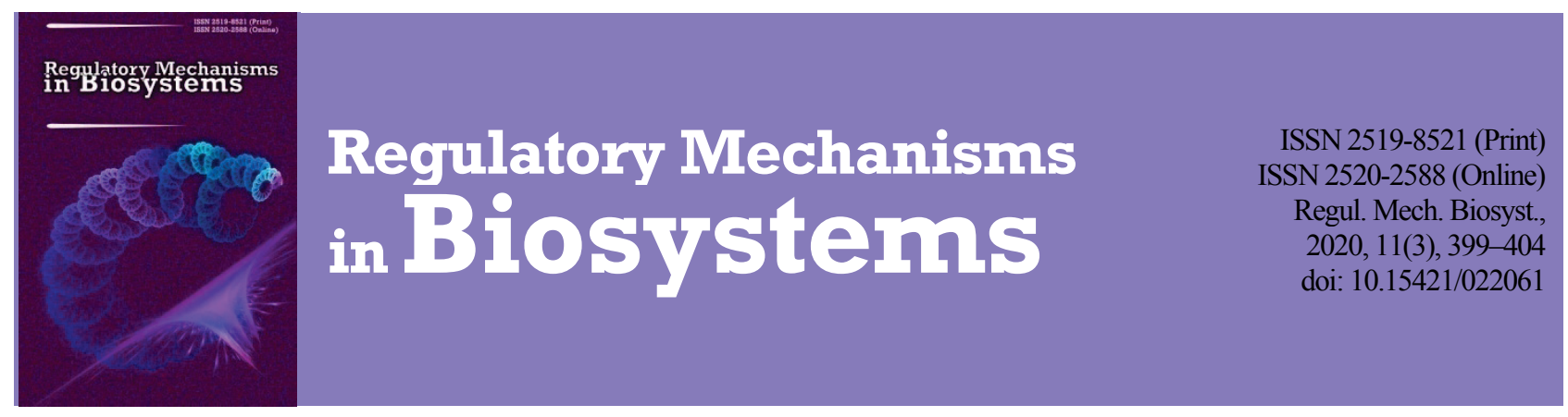

\title{
Sex identification of different species of wild birds using a single universal protocol to the bird sexing method based on gene polymorphism
}

\author{
S. V. Rudaya*, O. O. Katerynych*, M. V. Drahulian**, A. B. Chaplygina***, O. Y. Pakhomov**** \\ *State Poultry Research Station NAAS, Kharkiv region, Ukraine \\ **Matthias Erzberger Schule, Biberach, Germany \\ ***H. S. Skovoroda's Kharkiv National Pedagogical University, Kharkiv, Ukraine \\ ****Oles Honchar Dnipro National University, Dnipro, Ukraine
}

Article info

Received 04.06.2020

Received in revised form 11.07.2020

Accepted 13.07.2020

State Poultry Research

Station NAAS, Central st., 20

Birky, Kharkiv region, 63421

Ukraine. Tel.:+38-057-477-80-00

E-mail: sveta.ruda@gmail.com

Matthias Erzberger Schule, Leipzig st., 11,

Biberach, 88400, Germany.

Tel.:+49-157-512-05-099.

E-mail:m.drahulian@gmail.com

H. S. Skovoroda's

Kharkiv National Pedagogical

Kharkiv, Ukraine.

Tel.: +38-050-618-18-96

Oles Honchar Dnipro

National University,

Gagarin av., 72,

Tel.: +38-050-758-88-51.

E-mail:a.pakhomov@i.ua
University, Valentinovskaya st., 2,

E-mail: iturdus@ukr.net

Dnipro, 49010, Ukraine.

Rudaya, S. V., Katerynych, O. O., Drahulian, M. V., Chaplygina, A. B., \& Pakhomov, O. Y. (2020). Sex identification of different species of wild birds using a single universal protocol to the bird sexing method based on gene polymorphism. Regulatory Mechanisms in Biosystems, 11(3), 399-404. doi:10.15421/022061

This article presents an elaboration of the protocol for the method of sexing wild birds based on the polymorphism of the CHD gene using P2/P8 primer for Common Pheasant - Phasianus colchicus (Linnaeus, 1758; Galliformes, Phasianidae); Silver Lofur or Silver Pheasant - Lophura nycthemera (Linnaeus, 1758; Galliformes, Phasianidae), Budgerigar - Melopsittacus undulatus (Shaw, 1805; Psittaciformes, Psittacidae), Herring Gull - Larus argentatus (Pontoppidan, 1763; Charadriiformes, Laridae), and White Stork - Ciconia ciconia (Linnaeus, 1758; Ciconiiformes, Ciconiidae). Blood samples were taken from Common Pheasant, Silver Pheasant and White Stork using the "drop of blood on paper" method. For the Budgerigar and the Herring Gull, DNA was isolated from the feather follicle. To isolate DNA, a commercial NeoPrep 100 DNA reagent kit (Neogen, Ukraine) was used. Primers P2/P8 were used for PCR; PCR was performed using GenPac PCR Core reagents (Neogen, Ukraine). We selected the optimal amount of Tag polymerase, the amount of DNA and primers and, according to the amount of reagents, set acceptable amplification modes and electrophoresis agarose gel percentage. Prior to PCR, additional DNA gel electrophoresis purification is proposed, which increases the percentage of positive sex determination results. It was found that the ideal mixture for the 5 bird species was an amplification mixture (total volume $20 \mu \mathrm{L}$, containing $1 \mathrm{U}$ Tag polymerase, 100 ng DNA and $0.6 \mu \mathrm{M}$ of each primer). The amplified CHD-Z fragment of Common and Silver pheasants is of $\sim 340 \mathrm{n}$. p., CHD-W 360 n. p. Herring Gull and Budgerigar have $\sim 350$ n. p. of CHD-Z length, and 400 n. p. of CHD-W length, White Stork has its CHD-Z of $\sim 370$ n. p. long. It is advisable to investigate the genome of the experimental bird species using horizontal electrophoresis in agar's gel with the concentration of 5\%, which makes it possible to clearly visualize the female genotype. The universal protocol of the method of sex determination based on polymorphism of the CHD gene for the 5 studied bird species is described. These results of the study led to the conclusion that for the simultaneous sexing of several species of birds, it is advisable to develop a unified protocol for determining the status of the CHD gene, with the aim of clarifying the gender, as well as new approaches in ornithology and ecology aimed at determining interspecific differences associated with gene polymorphism. Identification of differences in fragment sizes may be useful for identifying the species in cases when birds form mixed pairings for taxonomic and phylogenetic comparisons.

Keywords: sexual dimorphism of birds; CHD-Z; CHD-W; P2/P8 primer; amplification modes

\section{Introduction}

Basic information about each living creature includes the information about its gender. However, sometimes, it is not easy to identify the difference between the sexes in different taxonomic groups. In dimorphic birds such as Bluethroat (Luscinia svecica (Linnaeus, 1758)), Redstart (Phoenicurus phoenicurus (Linnaeus, 1758)) and Golden Oriole (Oriolus oriolus (Linnaeus, 1758)), it is very easy to distinguish between males and females. But many species of birds do not have pronounced sexual dimorphism or acquire it only at puberty. Morphological measurements and sex determination by behaviour are not always reliable, only some adult birds can be sexed by morphometric analysis of the quantitative relationship between gender and body size or colour of feathers. In approximately $60 \%$ of bird species, adults do not have pronounced sexual dimorphism, that is, males and females are practically indistinguishable externally. The absence of pronounced sexual dimorphism in birds makes it difficult to study their behaviour, specific nutrition, and other important aspects of biology and ecology (Chaplygina et al., 2018, 2019). The use of morpho- metric analysis becomes more complicated when the body size and colour of feathers changes depending on regions and different geographical areas.

The ability to determine sex in the early stages of development is necessary for the correct ratio of females and males in bird groups when breeding. Errors in determining sex type often result in the failure of birds to breed in captivity (Zhang et al., 2012; He et al., 2013). The problem of sex determination is acute when performing activities aimed at preservation of rare and endangered bird species. The balance of the sex ratio in small populations plays an important role in preservation of endangered species (Wysocki, 2006; Cerit \& Avanus, 2007a; Dybus et al., 2009). It is possible to determine the sex of quail in such breeds as Estonian, Japanese and Manchurian only at the age of about 21-25 days. In other breeds, sex can be determined only when puberty is reached (Serebryakov, 2010). The sex of parrot chicks (Macaws, Budgerigars, African Grey Parrots, Cockatoos, Lories, etc.) is difficult to determine using only morphological measurements (Fomin, 2008). The chicks of Budgerigar, for instance, both females and males, have approximately the same light pink beak wax. Therefore, up to 40 days, it is impossible to reliably determine the 
sex of a Budgerigar. The situation is similar with some other species of birds (Chaplygina et al.,2020).

It is also worth noting that many species are capable of mixed pairings, as a result of which hybrid individuals appear. There are cytological methods of investigating bird species characteristics, on the basis of which the family can be identified. For example, we found differences in the leukocyte form in representatives of the Great Tit and two species of flycatchers (Collared and Pied): the basophile index of the Great Tit compared to the that of the Collared Flycatcher was, on average, by $5.41 \%$ lower $(5.71 \pm 1.79, \mathrm{P}<0.01)$, and compared with the corresponding index of Pied Flycatcher-by $4.00 \%$ (amounted to $4.33 \pm 0.42$, P $<0.001$ ). Also, the percentage of eosinophils and monocytes was higher in the blood of Great Tit by $1.29 \%$ and $2.61 \%$, compared to Collared and Pied Flycatchers, respectively (Drahulian et al., 2018a, 2018b). But such an analysis is only applicable to finding differences between families. In order to find differences between closely related species, and even more so, between genders, molecular genetic methods of analysis are used.

Microsatellite analysis (ISSR-PCR), for example, can be used for taxonomic and phylogenetic comparisons. The obtained spectra of amplification products, using primer (AGC) $6 \mathrm{G}$, can be particularly effective in studying the intra-breed genetic differentiation of adults and chicks of the flycatcher family (Drahulian et al., 2018b).

Bird sex is determined by sex chromosomes. Unlike mammals, that have an XY pair as the male sex determination, female birds are heterogametic. Females possess $\mathrm{Z}$ and $\mathrm{W}$ chromosomes, whereas males have only two $\mathrm{Z}$ chromosomes. The $\mathrm{W}$ chromosome refers to microchromosomes, in which there are genes that encode proteins, and genes that encode sequences of small nuclear RNA. The W chromosome has a high level of chromatization, which is not observed in $\mathrm{Z}$ chromosomes (Ellegren, 2001; Bondarenko \& Omar, 2013).

There are more than a dozen different methods of sexing birds, but in some cases they are not effective enough. Therefore, the use of alternative methods of sexing, based on modern molecular genetic approaches to solve the above mentioned problems is the primary and relevant attempt for determining the gender of birds at different stages of development (Ellegren, 2001; Kulibaba \& Ruda, 2012). The method of polymerase chain reaction (PCR) for studying polymorphism by sex chromosomes allows the sex of birds to be determined, when it is mainly impossible to do so by other methods (Sacchi et al., 2004; Cheng et al., 2006; Reddy et al., 2007; Kasuga et al.,2012).

One of the fundamental aspects is the difference in length of amplified fragments. CHD-Z and CHD-W vary within different species of birds and can be determined using agarose and polyacrylamide gels of various concentrations (Dubiec \& Zagalska-Neubauer, 2006; Cerit \& Avanus, 2007a). However, despite all the advantages, this method has certain limitations. In many bird species, the difference in the size of the amplicons of CHD-Z/CHD-W is so small that even the use of polyacrylamide gels often does not allow a reliable interpretation of the results. Therefore, the development of individual modes of amplification and concentration of agarose gel is an urgent methodological issue in the practical application of the polymerase chain reaction for determining the sex of birds, and interspecific and intraspecific polymorphism in different species of birds using the $\mathrm{CHD}$ genes.

As part of bird investigation in Kharkiv Zoological Park, we were interested in 5 species: Common Pheasant - Phasianus colchicus (Linnaeus, 1758); Silver Lofur or Silver Pheasant - Lophura nycthemera (Linnaeus,1758), Budgerigar - Melopsittacus undulatus (Shaw, 1805), Herring Gull - Larus argentatus (Pontoppidan, 1763), and White Stork Ciconia ciconia (Linnaeus, 1758). From literature sources, it is known that P2 / P8 primer is common in establishing sexual dimorphism in these birds, but the amount of DNA, tag polymerase, primers in the reaction mixture, amplification modes and the percentage of agarose gel during electrophoresis differs (Table 1).

Since it is possible to determine interspecific and intraspecific polymorphism for all species using a common primer, it is possible to develop a unified protocol for Ph. colchicus, L. nycthemera, M. undulatus, L. argentatus, and C. ciconia, choosing modes of amplification and concentration of DNA, tag polymerase, primers and agarose compatible for the above mentioned birds. That was the objective of our work.

\section{Table 1}

The length of fragments CHD-Z and CHD-W

when amplified with $\mathrm{P} 2 / \mathrm{P} 8$ primers

\begin{tabular}{lccccl}
\hline \multicolumn{1}{c}{ Species } & Primers & $\begin{array}{c}\text { Agarose Size of } C H D-Z \text { Size of CHD- } \\
\text { gel, \% }\end{array}$ & amplicon & W amplicon & \multicolumn{1}{c}{ Author } \\
\hline White Stork & $P 2 / P 8$ & 2 & 377 & 384 & Han et al., 2009 \\
Silver & $P 2 / P 8$ & 2 & 337 & 362 & Wang \& \\
Pheasant & 2 & & 344 & 396 & Zhang, 2009 \\
Budgerigar & $P 2 / P 8$ & - & Ogawa et al., 1997 \\
Herring Gull & $P 2 / P 8$ & 3 & 344 & 396 & Griffiths et al., 1998 \\
\hline
\end{tabular}

\section{Materials and methods}

The experiment was conducted in compliance with bioethics, in accordance with the provisions of the European Convention for the Protection of Vertebrate Animals Used for Experimental and Other Scientific Purposes.

The investigations were performed at the laboratory of molecular diagnostics of the National Research Station of Poultry, NRSP. The birds for research were provided by Kharkiv Zoological Park. For the analysis, the following objects were used (number of samples $=30$ ): Common Pheasant - Ph. colchicus $(\mathrm{n}=6)$; Silver Lofur or Silver Pheasant L. nycthemera $(\mathrm{n}=6)$; Budgerigar - M. undulatus $(\mathrm{n}=6)$; Herring Gull L. argentatus $(\mathrm{n}=6)$; White Stork - C. ciconia $(\mathrm{n}=6)$.

Blood samples were taken from the birds; Ph. colchicus, L. nyctheme$r a$ and C. ciconia using the modified "drop of blood on paper" method. The blood was collected on sterile filter paper; the sampling was performed using a sterile scarifier from the brachial vein to prevent infection of birds and mixing of genetic material. To avoid contamination, each sample was dried, labeled and individually packaged. This technique helps to reduce stress in birds and minimize damage. The DNA of female Gallus gallus was used as the control sample. In smaller birds, the Budgerigar and Herring Gull we used the feather follicle to avoid stress as a biomaterial. The work was performed in compliance with the standard procedure; when transferred to clean test-tubes, the samples were encoded according to the type of serial numbers. Further work (DNA isolation, amplification and electrophoresis) was performed with encoded material. For DNA extraction, a commercial NeoPrep100 DNA reagent kit (Neogen, Ukraine) was used. Isolation of DNA required for analysis was evaluated by $0.7 \%$ agarose gel electrophoresis (CSL-AG100, Cleaver Scientific, UK) at $200 \mathrm{~V}$ for $300 \mathrm{~s}$.

To control additional DNA purification, electrophoresis was performed on a $0.7 \%$ agarose gel (CSL-AG100, Cleaver Scientific, UK) at $200 \mathrm{~V}$ for $300 \mathrm{~s}$. Then the samples were placed on the transilluminator's light filter, including UV irradiation, and, observing through a protective glass (or glasses), the location of the target fragment was noted. Gel sections containing the target fragment containing DNA were excised and placed in $1.5 \mathrm{~mL}$ microtubes. Isolation of DNA from the gel was performed by centrifugation using Diatom DNA reagent kits. After that, the DNA concentration was measured using a spectrophotometer.

For PCR occurrence P2/P8 primers were used. Primers equences were: F5'-CTC-CCA-AGG-ATG-AGR-AAY-TG -3', R5'-TCT-GCATCG-CTA-AAT-CCT-TT-3' (Griffiths et al., 1998; Han et al., 2009; Wang \& Zhang, 2009; Dawson et al., 2016). PCR was performed using GenPac PCR Core reagents (Neogen, Ukraine), and Tertsik programmable thermal cycler. This reagent kit is a lyophilized, dry mix ready for DNA amplification. Each tube contained Tag polymerase inhibited for hot start Tag, deoxynucleoside triphosphates and a solution of magnesium chloride with final concentrations of $200 \mu \mathrm{M}, 2.5 \mathrm{mM}$, respectively, as well as an optimized buffer system for performing one standard PCR. The volume of the final mixture was $20 \mu \mathrm{L}$. The concentration of the primers was $0.6 \mu \mathrm{M}$. The tubes were carefully closed and transferred to a thermal cycler for PCR. The following components were added to the microtubes per one tube: $10 \mu \mathrm{L}$ of the reaction mixture, $5 \mu \mathrm{L}$ primers, $5 \mu \mathrm{L}$ test sample, 2 drops of special oil. The hybridization temperature of the primers was calculated using a program for calculating the properties of oligonucleotides. Amplification was performed according to the following program (Table 2). 
Table2

Amplification temperature parameters of CHDg ene of sex identification

\begin{tabular}{lccc}
\hline \multicolumn{1}{c}{ Amplification stages } & Temperature, ${ }^{\circ} \mathrm{C}$ & Time, $s$ & Cycles quantity \\
\hline DNA denaturation & 94 & 90 & 1 \\
Primers hybridization & 48 & 45 & 30 \\
Synthesis & 72 & 45 & 30 \\
Denaturation & 94 & 30 & 30 \\
Final synthesis & 72 & 600 & 1 \\
\hline \multicolumn{1}{c}{ Storage } & 4 & & - \\
\hline
\end{tabular}

Electrophoresis of amplification products was carried out using an agarose gel of different concentrations $-2 \%, 3 \%, 4 \%$ and $5 \%$. An agarose gel was prepared in a microwave oven on trisborate buffer (TBE buffer), with further addition of a solution of ethidium bromide. The composition of the TBE buffer per one liter, $\mathrm{pH}=8.3$ : Trilon $\mathrm{B}-0.93 \mathrm{~g}$ (production Synnad, China); tris-(hydromethyl)-aminomethane - $10.8 \mathrm{~g}$ (manufactured by Shanghai Synnad, China); boric acid $-5.5 \mathrm{~g}$ (manufactured by Eti mine works G. M., Turkey). The gel was poured into a special chamber, with the help of a comb, holes were formed for introducing samples and cooled. The finished gel was transferred to a horizontal electrophoresis apparatus. $10 \mu \mathrm{L}$ of sample, molecular weight marker and control sample were added to each well. Electrophoresis with an agarose gel concentration of $2 \%$ was carried out at $100 \mathrm{~V}$ for $80 \mathrm{~min} ; 3 \%$ at $100 \mathrm{~V}$ for $80 \mathrm{~min} ; 4 \%$ at $120 \mathrm{~V}$ for $80 \mathrm{~min} ; 5.0 \%$ at $120 \mathrm{~V}$ for 90 minutes. Amplicons were visualized using ethidium bromide in ultraviolet light. Amplicon size was determined using a molecular weight marker M-50. Determination of the birds' gender using the method applied in this investigation was based on the analysis of the obtained electrophoregrams. The phoregrams revealed the presence of CHD gene polymorphism in Z and $\mathrm{W}$ chromosomes. The presence of an additional CHD-W band along with the existing CHD-Z band indicated the female genotype. The presence of only one band (CHD-Z) indicated the male genotype.

The difference between females of different species of birds is determined by the difference in length of CHD gene intron, expressed in pairs of nucleotides, determined on the electrophoregram using a molecular weight marker. The smaller the difference, the more difficult it is to distinguish the stripes from each other. Therefore, for those species of birds in which the differences are minimal vertical electrophoresis in polyacrylamide gel was used, which has high resolution.

\section{Results}

The percentage of successful DNA isolation from a drop of blood on paper and from a pen follicle was $100 \%$. Of the genotyped birds, $53 \%$ were males and $47 \%$ were females. Among the genotyped Ph. colchicus, Ph. nycthemera, M. undulatus and C. ciconia $50 \%$ were females and $50 \%$ were males. Among representatives of $L$. argentatus $33 \%$ were females and $47 \%$ males.

We conducted a series of experiments with different concentrations of agarose gel $(2 \%, 3 \%, 4 \%$ and $5 \%)$ to establish the optimal concentration when determining the sex of birds. Using agarose gel with $3 \%$ concentration, the female genotype was visualized only in Common Pheasant (Ph. colchicus), Herring Gull (L. argentatus), and Budgerigar (M. undulatus). During DNA typing of Herring Gull and Budgerigar according to the CHD gene, the CHD-W genotype had a fragment of $\sim 400$ n. p., CHD-Z $\sim 350 \mathrm{n}$. p. The Common Pheasant DNA typing displayed the size of the CHD-W genotype to be $\sim 360$ n. p., CHD-Z 240 n. p. (Fig. 1). So far, we could not determine the sex of White Stork (C. ciconia). Silver Pheasant (L. nycthemera) samples showed the difference in length of DNA fragments to be insignificant, the bands almost merged, which required electrophoresis with a higher concentration of agarose gel for more accurate separation.

When analyzing the electrophoregram in 5\% agarose gel, we observed that the intron of CHD-W gene was smaller than the intron of $\mathrm{CHD}-\mathrm{Z}$ gene. It follows that the difference in the size of amplicons indicated the presence of $\mathrm{Z}$ and $\mathrm{W}$ polymorphism in these bird species (Fig. 2). In the Budgerigar, competition between chromosomes for primers was observed, the reaction was more active along one of the chromosomes. As a result, when determining the sex, the female Budgerigar had one of the bands paler. In the other species, this was not observed. All the samples of White Stork belonged to males.

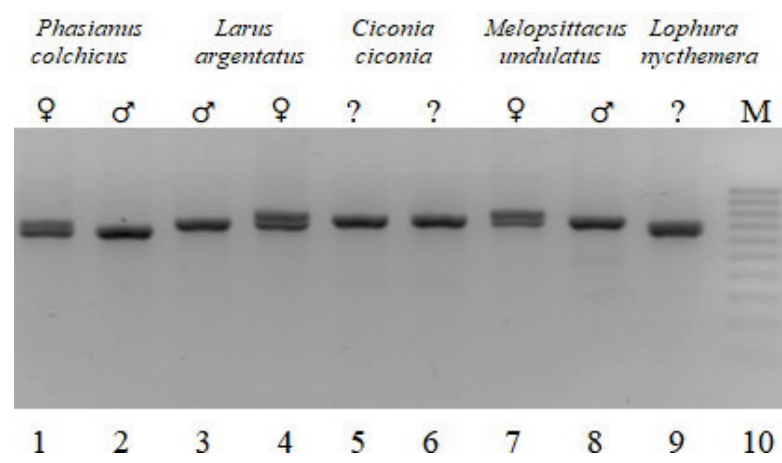

Fig. 1. Amplification products on 3\% agarose gel: 1,2-CHD-W 360 n. p., CHD-Z 240 n. p.; 3, 4, 7, 8-CHD-W $\sim 400$ n. p., CHD-Z 350 n. p.; 5, 6, 9- bands almost merge with CHD-W + CHD-Z 390 n. p., 10 - molecular weight marker M-50; "'?"-the difference in the length of DNA fragments is insignificant, which makes it impossible to identify the sex of the bird with $100 \%$ confidence

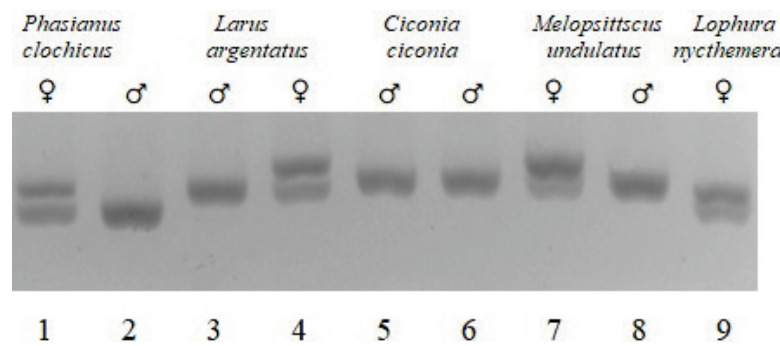

Fig. 2. Amplification products in 5\% agarose gel: $2,9-\mathrm{CHD}-\mathrm{W}$ 360 n. p., CHD-Z 340 n. p.; 3, 4, 7, 8-CHD-W 400 n. p., CHD-Z 350 n. p.; 5, 6-CHD-Z 370 n. p.

As the research results show, there is interspecific polymorphism of the intron of CHD gene. Moreover, differences in length of the amplified fragments of CHD-Z and CHD-W vary within different bird species and are determined using agarose gels of various concentrations. The presented bird species are characterized by different masses of amplicons The intron of CHD-Z gene in Common and Silver Pheasant had the largest molecular weight, and the intron of CHD-W gene in Herring Gull and Budgerigar had the smallest molecular weight. The amplified CHD$\mathrm{W}$ fragment in Common and Silver Pheasant was $\sim 360$ p. n., and CHD$\mathrm{Z} \sim 340$ p. n. Herring Gull and Budgerigar gene fragments were: CHD$\mathrm{W} \sim 400$ p. n., CHD-Z $\sim 350$ p. n.; White Stork CHD-Z $\sim 370$ p. n. The difference between the introns' amplicons of CHD-W and CHD-Z genes between Common Pheasant and Silver Pheasant was $\sim 20$ p. n.; between Herring Gull and Budgerigar- $50 \mathrm{p} . \mathrm{n}$.

As a universal protocol of sex identification for 5 species of birds, it is advisable to use horizontal electrophoresis in agarose gel with concentration of $5 \%$, which allows one to clearly visualize the female genotype (Fig. 2), while using lower concentrations, band divergence was not observed in some cases (Fig. 1).

\section{Discussion}

Comparison of the efficiency of DNA extraction from blood cells and feather follicle. Molecular genetic analysis is considered the most suitable for determining the sex of birds due to its high reliability, speed of execution and cost-effectiveness. Among the many genes associated with sex, the CHD gene has shown the greatest potential in the last decade as a universal marker for determining sex. But there are a diverse number of protocols for DNA isolation and copying the $\mathrm{CHD}$ gene by $\mathrm{PCR}$.

Since blood is an extremely rich source of DNA (due to the presence of nuclei in red blood cells), many researchers prefer taking 2-3 drops of it. Blood compares favourably with other biomaterials in that even a small amount of it allows, in addition to molecular genetic analysis, a smear for a micronucleus test (Drahulian et al., 2018a; Drahulian et al., 2018b). 
But over the past 30 years, the rapid development of molecular genetic methods has been noted, and today it has become possible to isolate DNA not only from the blood, but also from feathers (Drahulian et al., 2018b), kidneys, muscles, etc. (Ito et al., 2003). However, sometimes it is not possible to isolate DNA from a feather follicle. If heavy metals are present in the feather follicle, then the DNA is contaminated. When using feathers, there are also problems with insufficient DNA. The fact that a lesser or excessive amount of DNA can cause errors was mentioned, for example, by Nesterenko (2014). In our analysis, we used $100 \mathrm{ng}$ of DNA, in general, the amount of DNA for analysis in different authors varies $50-400 \mathrm{ng}$ (Ito et al., 2003; Dybus et al., 2009; Wang \& Zhang, 2009). Chinese scientists from the Biodiversity and Environmental Engineering Laboratory N. Wang \& Zhang (2009), when identifying the sex of pheasants, noted that $400 \mathrm{ng}$ of DNA is the optimal amount for PCR with P2/P8 primer. The effectiveness of successful sexing among pheasants was $91.0 \%$.

In general, it should be noted that if it is necessary to study exclusively the sex of the bird by PCR, the parameters that influence the choice of tissue for use as a sample are the degree of discomfort caused in the animal during sampling, and the degree of success of the analysis after using a certain type. In our case, DNA was $100.0 \%$ isolated from blood samples and the follicle of feathers, but nevertheless we prefer the selection of biomaterial in the form of venous blood, since in addition to molecular genetic studies, for example, a clinical blood test can also be carried out (Drahulian et al., 2018a) or the blood can be examined for the presence of heavy metals (Chaplygina \& Yuzyk, 2016).

In the above context, the doctoral work of Milos Vuchichevich, who studied 15 blood samples for sexing 5 species of birds (Amazona aestiva (Linnaeus, 1758), Psittacus erithacus (Linnaeus, 1758), Ara araranna (Linnaeus, 1758), Aratinga acuticaudata (Vieillot, 1818), Nymphicus hollandicus (Kerr, 1792)), is of interest. Despite the fact that all samples were successfully taken and in sufficient quantities, DNA was isolated, PCR sexing with $\mathrm{P} 2 / \mathrm{P} 8$ primers in one case (which is about $7 \%$ ) was unsuccessful. The reason for this, according to the author, could be the following circumstance: when isolating DNA, commercial kits were used that did not contain chemicals that neutralize inhibitors of PCR reaction (pigments, complex polysaccharides). All this jeopardizes the effectiveness of the analysis (Vuchichevich, 2014). Also in well-purified DNA, spectrometry for quantification will show more accurate results. And, as noted above, a specific concentration of DNA is prescribed - no more no less. In our work, we also used commercial kits, so we did not consider it superfluous to conduct additional DNA purification by gel electrophoresis.

Why do we need purification in principle? Gel electrophoresis purification is the separation of molecules by size. Porous gel particles allow molecules to move in order of decreasing size under the influence of an electric current. Smaller and larger molecules will be at opposite ends. Thus, the DNA mixture will be "cleaned" of excess impurities. Ethidium bromide also intercalates in DNA, decreasing spiralization by approximately 26, expanding the double helix and facilitating PCR.

Efficiency of CHD gene amplification protocol. In contaminated DNA samples, it is reasonable to expect the presence of numerous PCR reaction inhibitors, such as pigments, dead cells, RNA, various microorganisms, herbal ingredients in herbivorous products, or complex polysaccharides. The CHD gene is highly similar in birds and mammals (Bondarenko \& Omar, 2013), and if foreign material is present in the sample during PCR amplification, amplification of DNA fragments contaminating the CHD gene may predominate. Contamination can lead to the formation of PCR products, which after electrophoresis are visible as a single strip on the gel, as in the case of determining the male in birds. DNA isolated from feather follicles is thought to be more susceptible to these problems (Duan \& Fuerst, 2001). Different authors solve this problem in their own way. Thus, researchers at the Center for Cellular and Molecular Biology (Hyderabad Andhra Pradesh, India) perform restriction with HaemIII-restrictase enzyme (Reddy et al., 2007) before phoresis. Additional restriction by Haellis also described in the protocol for sexing a White Stork (Han et al., 2009). But in our case, we carried out additional purification by gel electrophoresis.

Another important factor in a successful reaction mode is the quality and quantity of Tag polymerase. Its concentration in the protocols ranged $0.40-1.75$ units in the amplification mixture and varied depending on the type of bird. So, for example, for Falconiformes -0.63 units for a total volume of $25 \mu \mathrm{L}$ of amplification mixture (Ito et al., 2003), for parrots and pheasants -1.00 units for a total volume of $20 \mu \mathrm{L}$ of amplification mixture (Kulibaba \& Ruda, 2012) for chickens - 1.50 units for a total volume of $25 \mu \mathrm{L}$, for pheasants -1.75 units for a total volume of $25 \mu \mathrm{L}$ (Wang \& Zhang, 2009). In experiments where a low amount of Tag polymerase was taken, the protocols showed a change in hybridization modes to $45^{\circ} \mathrm{C}$ (Ito et al., 2003), where there was more Tag polymerase in the amplification mixture, the temperature of hybridization was increased to $50^{\circ} \mathrm{C}$ (Wang \& Zhang, 2009). Properly selected primer concentration is also important. For example, when detecting the gender of Falconiformes and storks, $0.4 \mu \mathrm{M}$ of each primer per $100 \mathrm{ng}$ of DNA was added (Ito et al., 2003; Han et al., 2009), and Wang \& Zhang (2009), when identifying the sex of pheasants, added $0.8 \mu \mathrm{M}$ of each primer per $100 \mathrm{ng}$ of DNA. Moreover, the latter authors noted that, according to their experiments, the concentration of the primer is of great importance for $\mathrm{P} 2 / \mathrm{P} 8$ : the higher it is, the more effective the detection of the sex. At the indicated concentration of $0.8 \mu \mathrm{M}$ of each primer per $100 \mathrm{ng}$ of DNA, the authors achieved a performance of $91 \%$ (Wang \& Zhang, 2009). Since among the species studied by us there were also storks and pheasants, it was decided to take an average of $0.6 \mu \mathrm{M}$ of each primer per $100 \mathrm{ng}$ of DNA.

Optimal for the 5 bird species studied by us is 1.0 units Tag polymerase for a total volume of $20 \mu \mathrm{L}$ at a hybridization temperature of $48^{\circ} \mathrm{C}$. However, one should quote the words of Robertson and Gemmell that a general protocol for a large number of bird species is almost impossible to find, since the method is not suitable for all individuals, and even if it works in one population, it is not at all necessary that it will work in another (Robertson \& Gemmell, 2006). Therefore, it should be recognized that our positive results need additional verification in other populations.

Gel electrophoresis. An important factor is the correct concentration of the buffer and agarose gel. The most commonly used electrophoresis is Tris Acetate Buffer (TAE). TAE is a buffer solution containing Tris, acetic acid and EDTA (ethylenediaminetetraacetic acid). However, Tris borate buffer (TBE) is also used to study the polymorphism of the CHD gene (Ito et al., 2003; Vuchichevich, 2014). Moving away from the most commonly used TAE buffer in molecular genetics, we also use the TBE buffer. In Tris acetate, as a rule, resolution is better when separating fragments from $2000 \mathrm{bp}$ and longer than Tris borate, and also the speed of movement of such fragments is higher, but the buffer capacity is lower compared to Tris borate - it is depleted if driven long. In addition, TBE more efficiently separates short fragments - less than $2000 \mathrm{bp}$, and especially from $300 \mathrm{bp}$ and shorter in concentrated agarose. The concentration of the gel affects the resolution of DNA separation. An agarose gel consists of microscopic pores through which molecules pass, and there is an inverse relationship between the pore size of the agarose gel and concentration: the pore size decreases with increasing density of agarose fibers. A high gel concentration improves the separation of smaller DNA molecules, and a decrease in gel concentration allows the separation of large DNA molecules. The process allows one to separate fragments in the range from 50 base pairs to several mega bases, depending on the gel concentration used. Therefore, we tried to compare the data obtained for pheasants, storks, gulls and Budgerigars, in order to find a single universal, most preferred of all.

An employee of Ukrainian State Poultry Experimental Station Kulibaba (2015) also developed a method for determining the sex of birds (P. erithacus, Cacatua galerita (Latham, 1790), as well as representatives of the Musophagidae family) using polymerase chain reaction. The method was based on the polymerization of the CHD gene. She has found, as we did, that the use of $4-5 \%$ agarose gels for determining the lengths of amplified fragments is the most suitable concentration (Kulibaba, 2015).

Probably, the percentage of agarose gel can be much less if the distance between the amplitudes of CHD-Z and CHD-W is more than 50 p. n. So, researchers from the Vavilov Institute of General Genetics (RAN, Moscow), when conducting electrophoresis of the amplification products of sex marker EE0.6, used 1.5\% agarose gel for crane chicks (Mudrik et al., 2013). But in the process of polymerase chain reaction when determining the gender of the bird, artifacts can form, which are based on improperly selected amplification modes and low gel concentration. The questions of the number of cycles of denaturation / renaturation 
remain open (the probability of the formation of artifacts increases proportionally with an increase in the number of cycles), and also of the colouring method, which must be selected individually for each bird species. This should be especially taken into account for birds in which the difference between the sizes of the amplitudes CHD-Z and CHD-W is 2 20 p. n. These include Black Kite ( 2 p. n.), Golden Eagle ( 3 p. n.), Eastern Marsh Harrier (3 p. n.) (Han et al., 2009) and White Stork (7 p. n.) (Ito et al., 2003). All these species of birds are kept on the territory of the Kharkiv Zoological Park and, in the future, can also become objects of study when determining gender.

Some authors, when working with a number of bird species having a small difference in the length of CHD-W and CHD-Z fragments, propose the use of electrophoresis in $6 \%, 12 \%$, and $15 \%$ polyacrylate gel (Nesterenko, 2014). But we find such a technique unjustified in terms of the time spent on electrophoresis (4 hours at a voltage of $200 \mathrm{~V}$ ).

The indisputable advantage of our test system method on the experimental bird species is also that NO hyper duplexes form. As the experience of many researchers dealing with the issue of determining the sex of birds with small intervals between the sizes of the amplification showed, when hyper duplets appear, it is necessary to additionally select a primer, sometimes two or three (Wang et al., 2011; Kim et al., 2012). It should be noted, however, that the authors do not see anything negative in this, but this increases the cost of the method, as well as the additional time being taken to select the individual primers.

Minimizing errors in experiments is the most important task of the researcher. Therefore, it is necessary to achieve high accuracy. To increase the accuracy of determining the result, it is advisable to check the accuracy of the result by various methods. In our further studies, we plan to expand our test system to other bird species of Kharkov Zoological Park with a small difference in fragment lengths, for example, for storks, spoonbills, and some species of Falconidae. For storks, spoonbills, flamingos and some parrots, primers $2550 \mathrm{~F} / 2718 \mathrm{R}$ can be additionally used. These methods allow the sex of chicks in eggs to be determined.

\section{Conclusions}

Thus, the method of determining the sex of birds, based on the use of polymerase chain reaction, with a high degree of accuracy allows one to obtain a result for a large number of species simultaneously, which is a promising solution to the problem of determining the gender of birds living in zoological parks, reserves, making molecular genetic methods of sexing most effective and versatile. But like any technique, the method of sexing birds using PCR must be modified for certain species. This is especially important for species of birds that have a small difference between the amplicons of CHD-Z and CHD-W. Most often, blood is used to isolate DNA, but the biomaterial can be diverse, which affects the analysis protocols. As a rule, DNA that is isolated using commercial kits may contain substances that inhibit the polymerase chain reaction, therefore, in order to increase the effectiveness of the analysis, we proposed additional DNA purification using gel electrophoresis.

The next step is a molecular genetic study of CHD gene polymorphism, which requires preliminary preparation and comprehensive literature analysis, since the optimal PCR protocol with the indicated amount of DNA, primers, polymerase for one bird species may be ineffective for another, even closely related species. Given all the successful protocols, we have developed a single universal for Ph. colchicus, L. nycthemera, M. undulatus, L. argentatus and C. ciconia, which are kept in Kharkiv Zoological Park. For different species of birds, amplicons of different lengths were recorded. The difference in the length of introns CHD-Z and CHD-W of Herring Gull and Budgerigar is $\sim 50$ p. n., while that of Common and Silver pheasants is $\sim 20 \mathrm{p}$. n. This is a rather small distance, which is difficult to visualize in gel electrophoresis, therefore, the optimal concentration of agarose gel (5\%) was experimentally found, which also allows more clear separation of the bands in females with a small difference in length of intron to obtain reliable results.

\section{References}

Bondarenko, Y., \& Omar, H. (2013). Sravnitelnaya harakteristika i sovremennaya klassifikaciya metodov opredeleniya pola molodnyaka selskohozyajstvennoj pticy (analiticheskij obzor) [Comparative characteristics and modern classification of methods for determining the sex of young poultry (analytical review)]. Visnik Sumskogo Nacionalnogo Agramogo Universitetu, 23, 111-120 (in Russian).

Cerit, H., \& Avanus, K. (2007a). Sex identification in avian species using DNA typing methods. World's Poultry Science Journal, 63, 91-99.

Chaplygina, A., \& Yuzyk, D. (2016). The analysis of heavy metal concentrations in eggs of collared flycatchers, Ficedula albicollis (Passeriformes, Muscicapidae), and tits, Parus major, Parus caeruleus (Passeriformes, Paridae), in different areas of North-Eastern Ukraine. Vestnik Zoologii, 50(3), 259-266.

Chaplygina, A., Pakhomov, O., \& Brygadyrenko, V. (2019). Trophic links of the song thrush (Turdus philomelos) in transformed forest ecosystems of NorthEastern Ukraine. Biosystems Diversity. 27(1), 51-55.

Chaplygina, A., Pakhomov, O., Yevtushenko, H., \& Brygadyrenko, V. (2020). Trophic links of the chaffinch (Fringilla coelebs) in transformed forest ecosystems of North-Eastern Ukraine. Biosystems Diversity, 28(1), 92-97.

Chaplygina, A., Savynska, N., \& Brygadyrenko, V. (2018). Trophic Links of the spotted flycatcher, Muscicapa striata, in transformed forest ecosystems of North-Eastern Ukraine. Baltic Forestry, 24(2), 304-312.

Cheng, Y., Kuo, T., Lee, D., \& Weng, C. (2006). Sex identification of the blackfaced spoonbill (Platalea minor). Zoological Studies, 45(1), 104-113.

Dawson, D., Remedios, N., \& Horsburgh, G. (2016). A new marker based on the avian spindlin gene that is able to sex most birds, including species problematic to sex with CHD markers. Zoo Biology, 35(6), 533-545.

Drahulian, M., Chaplygina, A., Savynska, N., Kostenko, S., \& Buchek, P. (2018) Clinical blood analysis of the great tit Parus major. ScienceRise, 3, 11-14.

Drahulian, M., Chaplygina, A., Savynska, N., Kostenko, S., Ostrovsky, P., \& Gusar, K. (2018). The physiological and genetic differences between flycatcher (Ficedula albicollis vs. Ficedula hypoleuca). Folia Oecologica, 45(2), 111-119.

Duan, W., \& Fuerst, P. (2001). Isolation of a sex-linked DNA sequence in cranes. Journal of Heredity, 92, 392-397.

Dubiec, A., \& Zagalska-Neubauer, M. (2006). Molecular techniques for sex identification in birds. Biological Letters, 43(1), 3-12.

Dybus, A., Siemierz, A., Wysocki, D., Szatkowska, I., Muszyńska, M., \& Guenzel, S. (2009). Evaluation of the applicability of polymerase chain reaction (PCR) to sex identification in eurasian blackbirds (Turdus merula). Biological Letters, 46(1), 15-20.

Ellegren, H. (2001). Hens, cocks and avian sex identification: A quest for genes on Z or W? EMBO Reports, 2(3), 192-196.

Fomin, E. (2008). Sery'j popugaj zhako [The African Grey Parrot ]. Veche, Moscow.

Griffiths, R., Double, M., Orr, K., \& Dawson, R. (1998). ADNA test to sex most birds. Molecular Ecology, 7, 1071-1075.

Han, J., Jang, H., Cheong, S., Kim, S., Park, S., \& Na, K. (2009). Sex determination by PCR-RFLP in the oriental white stork Ciconia boyciana. Zoological Studies, 48(5), 619-624.

He, X., Qing, B., Han, J., \& Ding, C. (2013). Improved molecular assay for sex identification of the endangered crested ibis (Nipponia nippon) based on the CHD1 gene and a sex-linked microsatellite locus. Zoological Science, 30(9), $742-747$.

Ito, H., Sudo-Yamaji, A., Abe, M., Murase, T., \& Tsubota, T. (2003). Sex identification by alternative polymerase chain reaction method in Falconiformes. Zoological Science, 20, 339-344.

Kasuga, K., Higashi, M., Yamada, T., Sugiyama, T., Taniguchi, Y., Iwaisaki, H. (2012). The W- and Z-linked EEO.6 sequences used for molecular sexing of captive japanese crested ibis on Sado island. Animal Science Journal, 83(1), 83-87.

Kim, M., Lee, S., Lee, H., \& Lee, S. (2012). Molecular tools for species and sex identification in the mixed-species flocks of bean geese and white-fronted geese. Zoological Science, 29(11), 761-765.

Kulibaba, R. (2015). Utvorennya geterodupleksnoyi DNK pri amplifikaciyi fragmentiv geniv TGF-b2 ta CHD u ptahiv [The approval of heteroduplex DNA with amplification of fragments of TGF- $\beta 2$ and CHD genes in birds]. Scientific and Technical Bulletin of the Institute of Animal Husbandry of the National Academy of Agrarian Sciences of Ukraine, 114, 77-83 (in Ukrainian).

Kulibaba, R., \& Ruda, S. (2012). Opredelenie pola strausov s ispolzovaniem polimeraznoj cepnoj reakcii [Determination of sex of ostriches using polymerase chain reaction]. Ptakhivnytstvo, 68, 256-262 (in Russian).

Mudrik, A., Kashentseva, T., Hamburg, E., \& Gavrikova, E. (2013). Non-invasive method for identifying the gender of crane chicks by dna from capillary vessels of allantois. Ontogenes, 44(5), 372-376.

Nesterenko, O. (2014). Geneticheskie metody opredeleniya pola: Problemy i sposoby ih resheniya [Genetic methods for determining sex: Problems and methods for solving them]. Scientific Research in Zoological Parks, 30, 63-84 (in Russian).

Ogawa, A., Solovei, I., Hutchison, N., Saitoh, Y., Ikeda, J., Macgregor, H., \& Mizuno, S. (1997). Molecular characterization and cytological mapping of a non-repetitive DNA sequence region from the Wchromosome of chicken and itsuse as a universal probe for sexing Carinatae birds. Chromosome Research, 5, 93-101.

Reddy, A., Prakash, V., \& Shivaji, S. (2007). A rapid, non-invasive, PCR-based method for identification of sex of the endangered Old World vultures (white- 
backed and long-billed vultures) - Implications for captive breeding programmes. Current Science, 92(5), 659-662.

Robertson, B., \& Gemmell, N. (2006). PCR-based sexing in conservation biology: Wrong answer from an accurate methodology? Conservation Genetics, 7, 267-271.

Sacchi, P., Soglia, D., Maione, S., Meneguz, G., Campora, M., \& Rasero, R. (2004) A non-invasive test for sex identification in short-toed Eagle (Circaetus gallicus). Molecular and Cellular Probes, 18(3), 193-196.

Serebryakov, A. (2010). Perepela: Soderzhanie, kormlenie, razvedenie [Quail: Maintenance, feeding, breeding]. Penza Press, Penza (in Russian).

Vuchichevich, M. (2014). Analiza CHD gena ptica kao molekularnog markera za determinaciju pola [Analysis of the CHD gene in birds as a molecular marker for sex determination]. Belgrade (in Serbian).
Wang, N., \& Zhang, Z. (2009). The novel primers for sex identification in the brown eared-pheasant and their application to other species. Molecular Ecology Resources, 9, 186-188.

Wang, Z., Zhou, X., Lin, Q., Fang, W., \& Chen, X. (2011). New primers for sex identification in the Chinese egret and other ardeid species. Molecular Ecology Resources, 11(1), 176-179.

Wysocki, D. (2006). Factors affecting the between-season divorce rate in the urban population of European blackbird Turdus merula in North-Western Poland. Acta Ornithologica, 41, 71-78

Zhang, P., Han, J., Liu, Q., Zhang, J., \& Zhang, X. (2012). Sex identification of four penguin species using locus-specific PCR. Zoo Biology, 32, 257-261. 